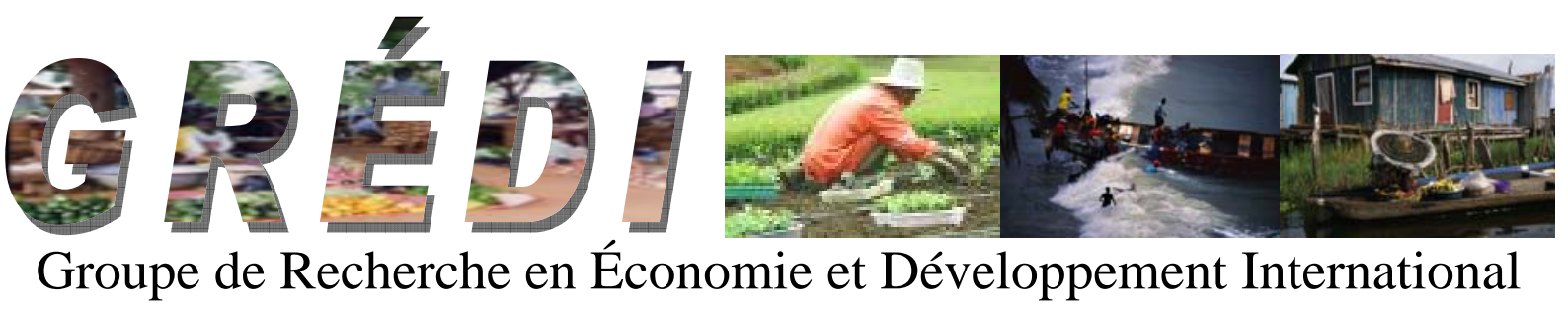

Cahier de recherche / Working Paper 08-25

Malmquist indexes with quasi-fixed inputs:

An application to school districts in Québec

\author{
Pierre Ouellette \\ Valérie Vierstraete
}




\title{
Malmquist indexes with quasi-fixed inputs: An application to school districts in Québec
}

Pierre Ouellette, Department of economics, Université du Québec à Montréal, C.P. 8888, succursale Centre-ville, Montréal, Québec, Canada H3C 3P8.

E-mail: ouellette.pierre@uqam.ca

Valérie Vierstraete, Department of economics, GREDI, Université de Sherbrooke, boulevard de l'Université, Sherbrooke, Québec, Canada J1K 2R1.

E-mail: valerie.vierstraete@usherbrooke.ca

\begin{abstract}
:
In a non-market environment, there is no pressure coming from competitors that leads firms toward efficiency. Public education system is the target of many critiques as being such an example of inefficiency. Some papers attempted to measure the level of inefficiency of schools or school districts using different methods. Unfortunately, those methods do not include an important aspect of the school management that is characterized by the incapacity to adjust some inputs like buildings and equipment to their optimal level. In this paper, we use a generalization of Malmquist indexes that introduces this lack of flexibility in the measurement of productivity and we apply this method in the case of school districts in the Province of Québec (Canada).
\end{abstract}

JEL classification: I1, D2.

Keywords: Data envelopment analysis, Efficiency, Productivity, Québec school districts. 


\section{Introduction}

Efficiency is always measured as a distance between what has been done and some concepts of what should have been done. According to the assumptions that have been retained, it is possible to use index number theory, parametric, or non-parametric methods to determine what should have been done. Obviously, the measure of (in)efficiency depends on the assumptions and the method used. Starting from Solow (1957)'s seminal paper, the economists's contribution is characterized by the desire to obtain a measure free from any assumptions. Paradoxically, relaxing the economic assumptions (i.e., constant returns to scale) has been accompanied by imposing more technical assumptions (i.e., choosing a functional form or imposing stochastic structure on error terms). There was a need to relax both economic and technical assumptions. This explains the recent rise of DEA as a substitute to parametric methods (even if Farrell proposed the method as early as 1957). This method has the advantage to relax most of the technical assumptions required by econometric methods.

The use of Malmquist (1953) indexes in the measurement of productivity has been introduced by Caves, Christensen and Diewert (1982). Unfortunately, their method required some strong behavioral assumptions: the firms should be cost minimisers or profit maximisers. Furthermore, it was necessary to have both price and quantity data on inputs and outputs. Finally, every input was supposed to be variable and firms were considered to be efficient. Färe et al. (1994) relaxed most of these assumptions. They proposed to use distance functions, defined as the reciprocal of Farrel's efficiency measure. This has important consequences. Price data are no longer needed, no behavioral assumptions are imposed, and, above all, it is possible to decompose productivity change in efficiency change and technological change: the assumption of efficiency is dropped. Nevertheless, the assumption that inputs can be freely adjusted is maintained.

In a companion paper (Ouellette and Vierstraete, 2004), we showed how to introduce quasifixed inputs in Malmquist indexes. By quasi-fixed inputs, we mean that those inputs cannot be freely adjusted to their optimal level in the short-run. This aspect is particularly important in public sectors, since they are characterized by large and bulky inputs. Adjusting those inputs is impossible in the short-run as a result of technical and/or administrative constraints. 
The quasi-fixity of some inputs constitutes a limitation to managers' ability to optimize the input bundle. Introducing this limitation is a necessity if we want to assess properly firms' efficiency.

We apply this method to the case of school districts in the Province of Québec (Canada). We will show that this constraint should be taken into account and that this helps in identifying the source of inefficiency.

\section{Distance functions without quasi-fixed inputs}

One can already find papers using Malmquist index of productivity in order to measure the efficiency and the technological change of different types of institutions. For example, Gannon (2008) studied hospitals and Asmild and Tam (2007) studied financial institutions. Others are studying educational institutions. Among them, Worthington and Lee (2008) evaluated the efficiency of Autralian universities, Flegg et al. (2004) did the same research for British universities, and Grosskopf and Moutray (2001) for the US high schools. However, all those papers include the assumption that each and every input could be set freely and instantly at the desired level. In other words, the inputs were all variable. The corresponding Malmquist index is presented in this section. The first piece of the puzzle is the distance function which is defined by:

$$
D^{t}\left(x^{t}, y^{t}\right)=\sup _{\beta}\left\{\beta: \frac{x^{t}}{\beta} \in L\left(y^{t}\right)\right\} \text {, }
$$

where $L\left(y^{t}\right)=\left\{x^{t}:\left(x^{t}, y^{t}\right) \in T^{t}\right\}$ is the input requirement set, $x^{t}$ is the input vector, and $y^{t}$, the vector of output. $T^{t}$ is the set of production possibilities at time t. $\frac{1}{\beta}$ is a scalar measuring the distance between the observed inputs-outputs bundle and the production frontier. Equivalently, we could write:

$$
D^{t}\left(x^{t}, y^{t}\right)^{-1}=\min _{\theta}\left\{\theta:\left(\theta x^{t}\right) \in L^{t}\left(y^{t}\right)\right\}
$$

where $\theta$ is the efficiency measure proposed by Farrell (1957). 
Färe et al. (1994) showed that it is possible to decompose the Malmquist productivity index into two components: an index of the change in efficiency and an index of technological change. The input-oriented Malmquist productivity index is defined by:

$$
M^{t+1}\left(x^{t+1}, y^{t+1}, x^{t}, y^{t}\right)=\left[\frac{D^{t}\left(x^{t+1}, y^{t+1}\right)}{D^{t}\left(x^{t}, y^{t}\right)} \times \frac{D^{t+1}\left(x^{t+1}, y^{t+1}\right)}{D^{t+1}\left(x^{t}, y^{t}\right)}\right]^{\frac{1}{2}} .
$$

In presence of technical change, this index would decrease. We could decompose the Malmquist index in two components, $M=E \times P$,

where $E=\frac{D^{t+1}\left(x^{t+1}, y^{t+1}\right)}{D^{t}\left(x^{t}, y^{t}\right)}$ measures the change in efficiency between $t$ and $t+1$,

and $P=\left[\frac{D^{t}\left(x^{t}, y^{t}\right)}{D^{t+1}\left(x^{t}, y^{t}\right)} \times \frac{D^{t}\left(x^{t+1}, y^{t+1}\right)}{D^{t+1}\left(x^{t+1}, y^{t+1}\right)}\right]^{\frac{1}{2}}$ measures the technological change between $t$ and $t+1$.

It follows that $M=\frac{D^{t+1}\left(x^{t+1}, y^{t+1}\right)}{D^{t}\left(x^{t}, y^{t}\right)} \times\left[\frac{D^{t}\left(x^{t}, y^{t}\right)}{D^{t+1}\left(x^{t}, y^{t}\right)} \times \frac{D^{t}\left(x^{t+1}, y^{t+1}\right)}{D^{t+1}\left(x^{t+1}, y^{t+1}\right)}\right]^{\frac{1}{2}}$.

An increase in the productivity $(M<1)$ can be the result of both an increase in efficiency $(E$ $<1)$ or the presence of technological change $(P<1)$.

\section{Distance functions and quasi-fixed inputs ${ }^{1}$}

The presence of large and bulky inputs is observed in most of industrial sectors. This might be the result of the very nature of the inputs (buildings, land, etc.) or the result of the regulatory or the administrative processes. For example, in the Province of Québec, school

\footnotetext{
${ }^{1}$ See Ouellette and Vierstraete (2004) for details.
} 
buildings cannot be freely adjusted. If additional classrooms were needed, this could only be done after a long process involving school managers, school district managers, and the provincial government. This implies that buildings are out of the control of school managers. It is possible for them to adjust some (variable) factors, but not the entire bundle of inputs. When evaluating the efficiency of school managers, it is necessary to recognize this fact. Banker and Morey (1986) first introduced quasi-fixed inputs - or non-discretionary inputsin the DEA method. Non-discretionary inputs have been then introduced in some health economics papers (see Steinmann et al., 2004; Puig-Junoy, 1998). In education, Ruggiero (2004) incorporated quasi-fixed inputs, but not in the context of Malmquist index. Introducing quasi-fixed inputs in the distance function can easily be done. Thus the variableinput oriented distance function is:

$$
\begin{gathered}
D^{t}\left(x^{t}, k^{t}, y^{t}\right)=\sup _{\beta}\left\{\beta:\left(\frac{x^{t}}{\beta}, k^{t}\right) \in L^{t}\left(y^{t}\right)\right\} \\
\text { or } D^{t}\left(x^{t}, k^{t}, y^{t}\right)^{-1}=\min _{\theta}\left\{\theta:\left(\theta x^{t}, k^{t}\right) \in L^{t}\left(y^{t}\right)\right\},
\end{gathered}
$$

with the same notation as earlier and $k^{t}$ being the vector of quasi-fixed inputs. $\theta=1 / \beta$ measures the distance between the variable input bundle and the production frontier, given the quasi-fixed inputs and the outputs. The input-oriented Malmquist productivity index is then defined as follows:

$$
M=\left[\frac{D^{t}\left(x^{t+1}, k^{t+1}, y^{t+1}\right)}{D^{t}\left(x^{t}, k^{t}, y^{t}\right)} \times \frac{D^{t+1}\left(x^{t+1}, k^{t+1}, y^{t+1}\right)}{D^{t+1}\left(x^{t}, k^{t}, y^{t}\right)}\right]^{\frac{1}{2}}
$$

and the decomposition is

$$
M=\frac{D^{t+1}\left(x^{t+1}, k^{t+1}, y^{t+1}\right)}{D^{t}\left(x^{t}, k^{t}, y^{t}\right)} \times\left[\frac{D^{t}\left(x^{t}, k^{t}, y^{t}\right)}{D^{t+1}\left(x^{t}, k^{t}, y^{t}\right)} \times \frac{D^{t}\left(x^{t+1}, k^{t+1}, y^{t+1}\right)}{D^{t+1}\left(x^{t+1}, k^{t+1}, y^{t+1}\right)}\right]^{\frac{1}{2}}=E \times P
$$


where $E=\frac{D^{t+1}\left(x^{t+1}, k^{t+1}, y^{t+1}\right)}{D^{t}\left(x^{t}, k^{t}, y^{t}\right)}$ measures the change in efficiency between $t$ and $t+1$, and $P=\left[\frac{D^{t}\left(x^{t}, k^{t}, y^{t}\right)}{D^{t+1}\left(x^{t}, k^{t}, y^{t}\right)} \times \frac{D^{t}\left(x^{t+1}, k^{t+1}, y^{t+1}\right)}{D^{t+1}\left(x^{t+1}, k^{t+1}, y^{t+1}\right)}\right]^{\frac{1}{2}}$ measures the technological change between $t$ and $t+1$.

It is possible to decompose further this relation to make the impact of the quasi-fixed inputs more explicit. First, we measure the impact of variable inputs on productivity index given the quasi-fixed inputs, and then, we measure the impact of the quasi-fixed inputs given the variable inputs.

Let $E_{X \bar{K}^{t}}=\frac{D^{t+1}\left(x^{t+1}, k^{t}, y^{t+1}\right)}{D^{t}\left(x^{t}, k^{t}, y^{t}\right)}$ and $E_{\bar{X}^{t+1} K}=\frac{D^{t+1}\left(x^{t+1}, k^{t+1}, y^{t+1}\right)}{D^{t}\left(x^{t+1}, k^{t}, y^{t+1}\right)}$, where $E_{X \bar{K}^{t}}$ measures the change in efficiency holding the quasi-fixed inputs at their initial level and $E_{\bar{X}^{t+1} K}$ measures the change in efficiency holding the variable inputs and the outputs at their final levels.

Similarly, two indexes of technological change can be defined:

$$
\begin{gathered}
P_{X \bar{K}^{t}}=\left[\frac{D^{t}\left(x^{t}, k^{t}, y^{t}\right)}{D^{t+1}\left(x^{t}, k^{t}, y^{t}\right)} \times \frac{D^{t}\left(x^{t+1}, k^{t}, y^{t+1}\right)}{D^{t+1}\left(x^{t+1}, k^{t}, y^{t+1}\right)}\right]^{\frac{1}{2}} \text { and } \\
P_{\bar{X}^{t+1} K}=\left[\frac{D^{t}\left(x^{t+1}, k^{t}, y^{t+1}\right)}{D^{t+1}\left(x^{t+1}, k^{t}, y^{t+1}\right)} \times \frac{D^{t}\left(x^{t+1}, k^{t+1}, y^{t+1}\right)}{D^{t+1}\left(x^{t+1}, k^{t+1}, y^{t+1}\right)}\right]^{\frac{1}{2}},
\end{gathered}
$$

where $P_{X \bar{K}^{t}}$ measures technological change holding the quasi-fixed inputs at their initial level and $P_{\bar{X}^{t+1} K}$ measures technological change holding the variable inputs and the outputs at their final levels.

It is immediate to show that: $M=\left\{E_{X \bar{K}^{t}} \times P_{X \bar{K}^{t}}\right\} \times\left\{E_{\bar{X}^{t+1} K} \times P_{\bar{X}^{t+1} K}\right\}$. 
The first term in brackets $\left\{E_{X \bar{K}^{t}} \times P_{X \bar{K}^{t}}\right\}$ is the Malmquist productivity index when quasifixed inputs are stacked at their initial level:

$\left\{E_{X \bar{K}^{t}} \times P_{X \bar{K}^{t}}\right\}=M_{X \bar{K}^{t}}=\left[\frac{D^{t}\left(x^{t+1}, k^{t}, y^{t+1}\right)}{D^{t}\left(x^{t}, k^{t}, y^{t}\right)} \times \frac{D^{t+1}\left(x^{t+1}, k^{t}, y^{t+1}\right)}{D^{t+1}\left(x^{t}, k^{t}, y^{t}\right)}\right]^{\frac{1}{2}}$.

The second term in brackets $\left\{E_{\bar{X}^{t+1} K} \times P_{\bar{X}^{t+1} K}\right\}$ is also a Malmquist productivity index, but this time, when variable inputs and outputs are stacked at their final level:

$\left\{E_{\bar{X}^{t+1} K} \times P_{\bar{X}^{t+1} K}\right\}=M_{\bar{X}^{t+1} K}=\left[\frac{D^{t}\left(x^{t+1}, k^{t+1}, y^{t+1}\right)}{D^{t}\left(x^{t+1}, k^{t}, y^{t+1}\right)} \times \frac{D^{t+1}\left(x^{t+1}, k^{t+1}, y^{t+1}\right)}{D^{t+1}\left(x^{t+1}, k^{t}, y^{t+1}\right)}\right]^{\frac{1}{2}}$.

\section{Constant vs. variable returns to scale}

In the preceding sections, we voluntarily set the question of returns to scale aside. GrifellTatjé and Lovell (1995) in an influential paper showed that Malmquist indexes might lead to strong bias when compared with Total Factor Productivity (TFP) if it was used with variable returns to scale (VRS) distance functions. As shown by Lambert (1999), this is caused by the omission of the scale effect since TFP measure assumes constant returns to scale technology. It is necessary to introduce the scale effect if we want to obtain a valid measure.

\section{IV.1 Distance functions}

In order to simplify the burden of notation, we will assume from now on, that in sections II and III, the distance functions and every index were defined for VRS-technologies, that is, for the decision making unit " 0 " $\left(D M U_{0}\right)$, the input-oriented distance function $D^{T}\left(x^{\rho}, k^{\tau}, y^{\rho}\right)$ is approximated using the following linear program:

$$
D^{T}\left(x_{0}^{\rho}, k_{0}^{\tau}, y_{0}^{\rho}\right)^{-1}=\min _{\theta, \lambda}\{\theta\}
$$

subject to: 


$$
\begin{aligned}
& \sum_{n=1}^{N} \lambda_{n} y_{m, n}^{T} \geq y_{m, o}^{\rho}, \text { for all } m=1, \ldots, M \\
& \sum_{n=1}^{N} \lambda_{n} x_{r, n}^{T} \leq \theta x_{r, o}^{\rho}, \text { for all } r=1, \ldots, R \\
& \sum_{n=1}^{N} \lambda_{n} k_{s, n}^{T} \leq k_{s, o}^{\tau}, \text { for all } s=1, \ldots, S \\
& \sum_{n=1}^{N} \lambda_{n}=1 \\
& \lambda_{n} \geq 0, \text { for all } n=1, \ldots, N
\end{aligned}
$$

where $T, \rho, \tau=t$ or $t+1$, and $N$ is the total number of DMUs. Let us note that the constraint $\sum_{n=1}^{N} \lambda_{n}=1$ is introduced in order to prevent the technology from being a cone, so that the returns to scale are not necessarily constant. In order to distinguish between VRS- and CRStechnologies, we adopt the notation rule that for the CRS distance function the subscript " $c$ " is added. For example, the CRS-distance function is defined by:

$$
D_{c}^{T}\left(x_{0}^{\rho}, k_{0}^{\tau}, y_{0}^{\rho}\right)^{-1}=\min _{\theta, \lambda}\{\theta\}
$$

subject to:

$$
\begin{aligned}
& \sum_{n=1}^{N} \lambda_{n} y_{m, n}^{T} \geq y_{m, o}^{\rho}, \text { for all } m=1, \ldots, M \\
& \sum_{n=1}^{N} \lambda_{n} x_{r, n}^{T} \leq \theta x_{r, o}^{\rho}, \text { for all } r=1, \ldots, R \\
& \sum_{n=1}^{N} \lambda_{n} k_{s, n}^{T} \leq k_{s, o}^{\tau}, \text { for all } s=1, \ldots, S \\
& \lambda_{n} \geq 0, \text { for all } n=1, \ldots, N
\end{aligned}
$$

In the preceding section, we defined the Malmquist index of productivity change. Using our notation, this means that, since the distance function were not indexed by " $c$ ", this was a VRS-Malmquist index. For the sake of clarity, we will rewrite this index as:

$$
M^{V R S}=\left\{E_{X \bar{K}^{t}} \times P_{X \bar{K}^{t}}\right\} \times\left\{E_{\bar{X}^{t+1} K} \times P_{\bar{X}^{t+1} K}\right\} .
$$


In the sequel of this section, we will establish the link between the VRS Malmquist index and the CRS Malmquist index.

\section{IV.2 CRS Malmquist index}

The CRS Malmquist index of productivity change is defined as:

$$
M_{C R S}^{t}=\left[\frac{D_{C}^{t}\left(x^{t+1}, k^{t+1}, y^{t+1}\right)}{D_{C}^{t}\left(x^{t}, k^{t}, y^{t}\right)} * \frac{D_{C}^{t+1}\left(x^{t+1}, k^{t+1}, y^{t+1}\right)}{D_{C}^{t+1}\left(x^{t}, k^{t}, y^{t}\right)}\right]^{1 / 2} .
$$

After multiplying equation (1) by:

$$
\left[\frac{D_{C}^{t}\left(x^{t}, k^{t}, y^{t}\right)}{D_{C}^{t}\left(x^{t}, k^{t}, y^{t}\right)} \times \frac{D_{C}^{t+1}\left(x^{t+1}, k^{t+1}, y^{t+1}\right)}{D_{C}^{t+1}\left(x^{t+1}, k^{t+1}, y^{t+1}\right)}\right]^{1 / 2},
$$

one can decompose this index as follows:

$$
\begin{aligned}
M^{C R S}=\overbrace{\frac{D_{C}^{t+1}\left(x^{t+1}, k^{t+1}, y^{t+1}\right)}{D_{C}^{t}\left(x^{t}, k^{t}, y^{t}\right)} \times}^{\text {Ineficiency change } \mathrm{E})} \times \overbrace{\left[\frac{D_{C}^{t}\left(x^{t}, k^{t}, y^{t}\right)}{D_{C}^{t+1}\left(x^{t}, k^{t}, y^{t}\right)} \times \frac{D_{C}^{t}\left(x^{t+1}, k^{t+1}, y^{t+1}\right)}{D_{C}^{t+1}\left(x^{t+1}, k^{t+1}, y^{t+1}\right)}\right]^{1 / 2}}^{\text {Technological change (P) }}, \\
=E^{C R S} \times P^{C R S},
\end{aligned}
$$

where $E^{C R S}$ is the change in inefficiency and $P^{C R S}$ is the measure of technological change. These measures are defined for constant returns to scale (CRS) technology. After some rewritings, it is possible to adapt these measures in such a way that both measures are defined for variable returns to scale (VRS). We first multiply (2) by

$$
\frac{D^{t+1}\left(x^{t+1}, k^{t+1}, y^{t+1}\right)}{D^{t}\left(x^{t}, k^{t}, y^{t}\right)} \times \frac{D^{t}\left(x^{t}, k^{t}, y^{t}\right)}{D^{t+1}\left(x^{t+1}, k^{t+1}, y^{t+1}\right)} .
$$

It follows that:

$$
M^{C R S}=\overbrace{\frac{D^{t+1}\left(x^{t+1}, k^{t+1}, y^{t+1}\right)}{D^{t}\left(x^{t}, k^{t}, y^{t}\right)}}^{\begin{array}{c}
\text { Pure } \\
\text { efficiency } \\
\text { change }
\end{array}} \times \overbrace{\left[\frac{D_{C}^{t}\left(x^{t}, k^{t}, y^{t}\right)}{D_{C}^{t+1}\left(x^{t}, k^{t}, y^{t}\right)} \times \frac{D_{C}^{t}\left(x^{t+1}, k^{t+1}, y^{t+1}\right)}{D_{C}^{t+1}\left(x^{t+1}, k^{t+1}, y^{t+1}\right)}\right]^{1 / 2}}^{\begin{array}{c}
\text { Technological } \\
\text { change }
\end{array}}
$$




$$
\begin{aligned}
& \times \underbrace{\left[\frac{D^{t}\left(x^{t}, k^{t}, y^{t}\right) / D_{C}^{t}\left(x^{t}, k^{t}, y^{t}\right)}{D^{t+1}\left(x^{t+1}, k^{t+1}, y^{t+1}\right) / D_{t+1}^{t+1}\left(x^{t+1}, k^{t+1}, y^{t+1}\right)}\right]}_{\substack{\text { Seale } \\
\text { efliciency } \\
\text { change }}} . \\
& M^{C R S}=E^{V R S} \times P^{C R S} \times S .
\end{aligned}
$$

The term $E^{V R S}$ differs from $E^{C R S}$ in that the technology represented by the distance function is no longer restricted to constant returns to scale. The term $S$ is a measure of the impact of the change in the scale efficiency as measured by the distance between the CRS-technology and the VRS-technology.

One can do the same for the technological change index. It is necessary to multiply equation (3) by:

$$
\left[\frac{D^{t}\left(x^{t}, k^{t}, y^{t}\right)}{D^{t+1}\left(x^{t}, k^{t}, y^{t}\right)} \times \frac{D^{t}\left(x^{t+1}, k^{t+1}, y^{t+1}\right)}{D^{t+1}\left(x^{t+1}, k^{t+1}, y^{t+1}\right)}\right]^{1 / 2} \times\left[\frac{D^{t+1}\left(x^{t}, k^{t}, y^{t}\right)}{D^{t}\left(x^{t}, k^{t}, y^{t}\right)} \times \frac{D^{t+1}\left(x^{t+1}, k^{t+1}, y^{t+1}\right)}{D^{t}\left(x^{t+1}, k^{t+1}, y^{t+1}\right)}\right]^{1 / 2},
$$

so that:

$$
\begin{aligned}
M^{C R S}= & \overbrace{\frac{D^{t+1}\left(x^{t+1}, k^{t+1}, y^{t+1}\right)}{D^{t}\left(x^{t}, k^{t}, y^{t}\right)} \times \overbrace{\left[\frac{D^{t}\left(x^{t}, k^{t}, y^{t}\right)}{\text { erficiency }^{t+1}\left(x^{t}, k^{t}, y^{t}\right)} \times \frac{D^{t}\left(x^{t+1}, k^{t+1}, y^{t+1}\right)}{D^{t+1}\left(x^{t+1}, k^{t+1}, y^{t+1}\right)}\right]^{1 / 2}}^{\begin{array}{c}
\text { Technological } \\
\text { changeg }
\end{array}}} \\
& \times \frac{D_{C}^{t+1}\left(x^{t+1}, k^{t+1}, y^{t+1}\right) / D^{t+1}\left(x^{t+1}, k^{t+1}, y^{t+1}\right)}{D_{C}^{t}\left(x^{t}, k^{t}, y^{t}\right) / D^{t}\left(x^{t}, k^{t}, y^{t}\right)} \\
& \times\left[\frac{D_{C}^{t}\left(x^{t}, k^{t}, y^{t}\right) / D^{t}\left(x^{t}, k^{t}, y^{t}\right)}{D_{C}^{t+1}\left(x^{t}, k^{t}, y^{t}\right) / D^{t+1}\left(x^{t}, k^{t}, y^{t}\right)} \times \frac{D_{C}^{t}\left(x^{t+1}, k^{t+1}, y^{t+1}\right) / D^{t}\left(x^{t+1}, k^{t+1}, y^{t+1}\right)}{D_{C}^{t+1}\left(x^{t+1}, k^{t+1}, y^{t+1}\right) / D^{t+1}\left(x^{t+1}, k^{t+1}, y^{t+1}\right)}\right]^{1 / 2} .
\end{aligned}
$$

This can be rewritten as:

$$
M^{C R S}=E^{V R S} \times P^{V R S} \times S \times S T C,
$$

where $P^{V R S}$ is the measure of technological change for a VRS technology and the fourth term on the right hand side, written as STC, is defined by Zofio (2007) as the Scale bias Technological Change. It measures the impact of technological change on the scale effect. 
The product of the first two terms $E^{V R S} \times P^{V R S}=M^{V R S}$ is in fact the Malmquist index of productivity change for a VRS technology. The relation between both the CRS and the VRS indexes is $M^{C R S}=M^{V R S} \times S \times S T C$.

Finally, the CRS Malmquist index of productivity change can be decomposed as follows:

$$
M^{C R S}=\left\{E_{x \bar{K}^{t}}^{V R S} \times P_{x \bar{K}^{t}}^{V R S}\right\} \times\left\{E_{\bar{x}^{t+1} K}^{V R S} \times P_{\bar{x}^{t+1} K}^{V R S}\right\} \times S \times S T C .
$$

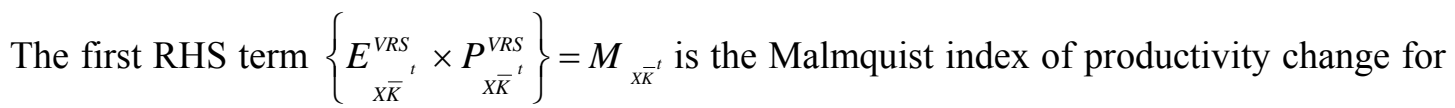
a VRS technology when the quasi-fixed inputs are held constant (at their initial level), the second RHS term $\left\{E_{\bar{X}^{t+1} K}^{V R S} \times P_{\bar{X}^{t+1} K}^{V R S}\right\}=M_{\bar{X}^{t+1} K}$ is the Malmquist index of productivity change for a VRS technology when the variable inputs and the outputs are held constant (at their final level), the third RHS term represents the impact of the scale effect change, and, finally, the fourth RHS term measures the bias of technological change on the scale effect.

\section{Data}

In Canada, education is under the control of provincial governments. The management of public schools is controlled by school districts and the provincial department of education controls these school districts. The provincial government heavily grants school districts. In turn, they must inform the government about every dollar received and spent. Thus they must complete, year after year, a detailed financial report and a report on the clientele. The Québec department of education accepted to share with us all those reports for the period 1992/93 to 1997/98.

Measuring the output of the education sector is an open question. Ideally, it would be possible to measure the output using a vector representing both the quantity and the quality of education produced by schools. That output would be "net" of the contribution of parents and any other factor influencing the level of education attained by a student. Of course, by education, we mean the complete set of knowledge mastered by any citizen of a country. This includes not only the professional knowledge, but also the ability to live in society. 
Unfortunately, this definition of education is out of reach using known data banks. As many before us, we will measure the outputs using more readily available data (see for example, Rassouli-Currier, 2007, Coates and Lamdin, 2002, Chakraborty et al, 2001). Our first output is the number of full time equivalent students attending primary (including kindergarten) schools. The second output is the number of full time equivalent students at the secondary level.

Our choice of output measures needs a discussion. It would have been possible to measure the output by the number of students receiving a diploma from their secondary schools (Kirjavainen and Loikkanen, 1998). The choice between the number of diploma and the number of students is a choice between two points of view about the role and impact of schools in a society. By choosing the number of diplomas it would mean that the other students, those without a diploma, did not receive anything from their school-years. Obviously, this is an extreme point of view contradicting the fact that schools help to socialize children and also that what has been learned has no value for those leaving Québec primary and secondary schools without a diploma.

Using this argument, it would be preferable to measure the number of students in every single year, since the "output" of any school year is not fully comparable to the others. This would have a negative counterpart since the number of outputs would increase from two to twelve. Our choice reflects the fact that DEA is quite sensible to the number of outputs, so there was a need to agregate categories of outputs.

Naturaly, and this is the case in any empirical works, our measure of inefficiency will include the impact of the characteristics left aside, such as the impact of parental guidance and social environment that might differ between two schools.

In order to "produce" education, school districts make use of many inputs. Some of them (the variable inputs) are closely related to the number of students, while some others (the quasifixed inputs) are not. The first variable input is the number of full time equivalent teachers. The second variable input is the full time equivalent number of non-teaching employees. A third variable input is energy. For each school district, the provincial department of education gave us the expenditure and the quantity for each type of energy for every building used in every school district. The price of each type of energy has been calculated dividing 
expenditure by the quantity. We then computed a Fisher quantity index of energy. Material and furniture (tables, desks, blackboards, papers, etc.) is the fourth variable input. The quantity index is given by the ratio of expenditure over the price index of furniture given by Statistics Canada. Finally, a fifth variable input has been calculated from the other expenditures not already mentioned (teaching and non teaching labors, energy, furniture) divided by a general price index, the implicit price index of the gross domestic demand. The only quasi-fixed input is the total square meters of buildings.

It would have been preferable to conduct our experiment independently for both the primary and the secondary schools. Unfortunately, the school boards do not publish the data for the two levels of education separately.

Our data is made up of 142 school districts over 6 years (that is 852 DMUs). For each DMU, we gathered data such that we get two outputs, 5 variable inputs and one quasi-fixed input. The complete descriptive statistics can be found in appendix 1.

\section{Results}

\section{VI.1 Impact of non constant returns to scale}

For each school district $(N=142)$ and for each year $(t=1$ to 6$)$, we calculated the inputoriented distance functions. Then, for each school district, we calculated 26 distance functions for a total of 3692 distance functions. ${ }^{2}$ Results for each region are shown in

${ }^{2}$ As mentioned by Färe et al. (1994), there is a possibility that no solution exists since we used inputoriented problems. When the problem arose, we could relax the convexity constraint $\sum_{n=1}^{N} \lambda_{n}=1$ (which implies variable returns to scale), to rather impose $\sum_{n=1}^{N} \lambda_{n} \leq 1$ (implying non-increasing returns to scale) and we could also completely relax that constraint, that is, $\sum_{n=1}^{N} \lambda_{n}$ is free (implying constant returns to scale). We thus would have 25 distance functions with non increasing returns to scale and 22 distance functions for which constant returns to scale would have been imposed. Furthermore, 36 distance functions remain infeasible. For the sake of comparability, we preferred to exclude all the DMUs for which we couldn't calculate distance functions with variable returns to scale. From the 
Appendix 2 and Appendix 3. As for Burgess and Wilson (1995), we calculated the geometric mean for each region.

We first observe that the CRS and the VRS Malmquist productivity indexes are very similar. As shown in Table 1 and Figure $1,{ }^{3}$ the pure scale effect $(S)$ is very close to 1 , so that we cannot use this argument to explain the evolution and the level of the productivity index $\left(M^{C R S}\right)$. Also, the technological bias on the scale effect $(S T C)$ is close to 1. For those reasons, the CRS-Malmquist productivity index is almost exclusively explained by the VRSMalmquist productivity index.

Second, we note that the initial decrease in productivity $\left(M^{C R S}=1.050\right.$ in 1992/93) has been compensated by an immediate increase $\left(M^{C R S}=0.987\right.$ in 1993/94). This gain has been maintained during the period $\left(M^{C R S}=0.9995\right.$ in 1996/97) even if we witnessed a decrease in VRS-productivity $\left(M^{V R S}=1.013\right.$ in 1996/97) because this decrease has been counterbalanced by an increase in productivity due to STC $(\mathrm{STC}=0.984)$.

Table 1. Decomposition of the CRS-Malmquist productivity index

\begin{tabular}{|c|cccc|}
\hline Year & $M^{C R S}$ & $M^{\text {VRS }}$ & $S$ & $S T C$ \\
\hline $1992 / 93$ & 1.0503 & 1.0526 & 0.9969 & 1.0009 \\
$1993 / 94$ & 0.9874 & 0.9894 & 1.0015 & 0.9963 \\
$1994 / 95$ & 0.9915 & 0.9830 & 1.0007 & 1.0079 \\
$1995 / 96$ & 0.9989 & 1.0064 & 0.9990 & 0.9931 \\
$1996 / 97$ & 0.9995 & 1.0132 & 1.0022 & 0.9839 \\
\hline
\end{tabular}

$M^{C R S}$ is the CRS-Malmquist input based productivity index, $M^{V R S}$ is the VRS-

Malmquist input based productivity index, $S$ is the scale effect, and STC is the bias of technological change on the scale effect. As noted in footnote 2, in some cases the convergence has not been achieved in the VRS case. The averages are calculated for the DMUs for which the convergence has been achieved with VRS.

remaining 3,328 distance functions, we calculated the above indexes. The number of DMUs excluded represents less than $2.5 \%$ of the sample.

${ }^{3}$ See Appendices 2, 3 and 4 for the results for each region. 


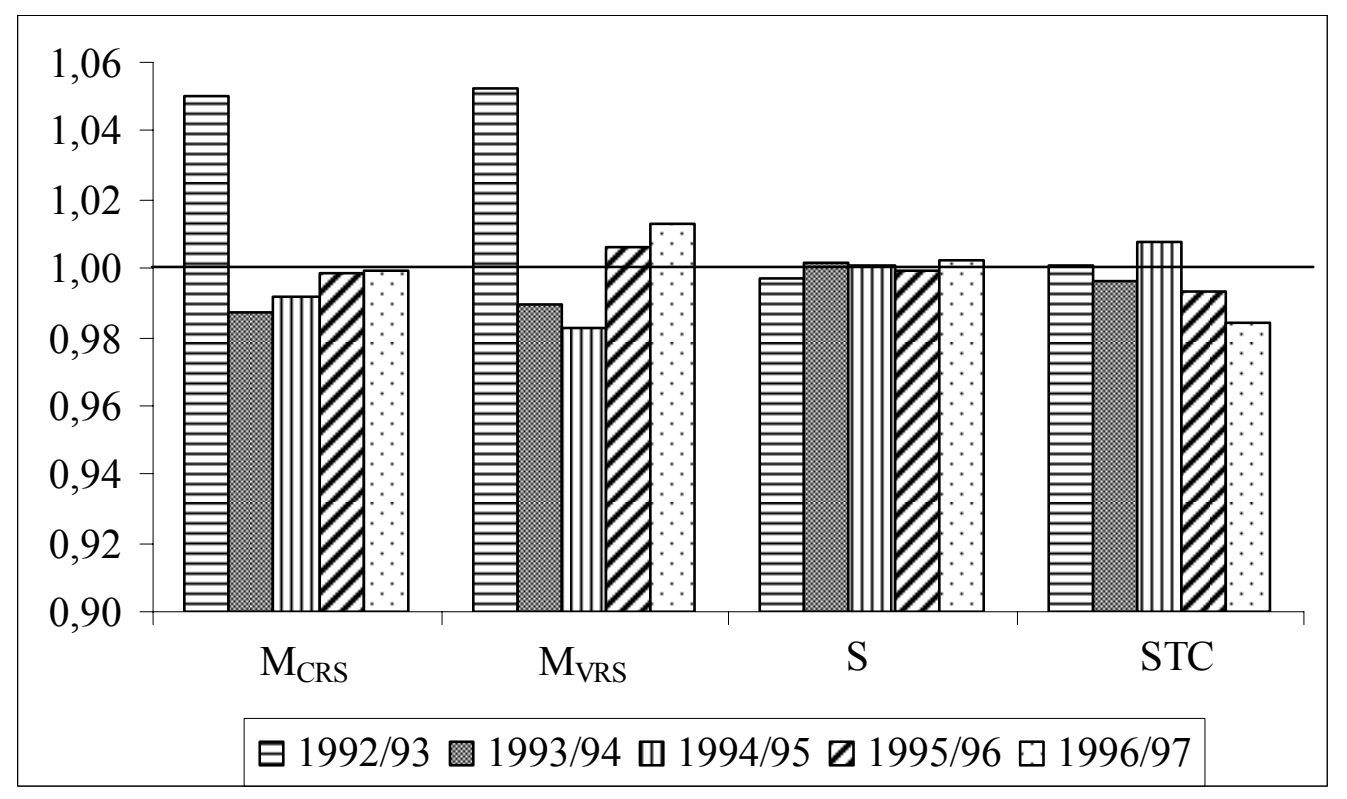

Figure 1. Decomposition of the CRS-Malmquist input based productivity index

Let us note that the results differ among regions (see Appendix 2). During the first period, we observed a decrease in productivity in every region, but in the other periods, the results become dissimilar. There is no obvious pattern among regions with high or low productivity changes. For example, Côte-Nord, a rural region with a very low population density, shows the biggest decrease in productivity in 1993/94 - 1994/95 $\left(\mathrm{M}^{\mathrm{CRS}}=1.007\right)$, but in the next year, this is Montréal, the most industrialized region in Québec with the highest population density, that shares the same record $\left(\mathrm{M}^{\mathrm{CRS}}=1.005\right)$.

\section{VI.2 Decomposition of the VRS-Malmquist input based productivity index}

We first use the decomposition of the VRS-Malmquist productivity index $\left(M^{V R S}\right)$ in its two components: the change in efficiency $\left(E^{V R S}\right)$ and the technological change $\left(P^{V R S}\right)$. The results are shown in Table 2 and Figure 2. 
Table 2. First decomposition of the VRS Malmquist productivity index

\begin{tabular}{|c|ccc|}
\hline Year & $M^{V R S}$ & $E^{V R S}$ & $P^{V R S}$ \\
\hline $1992 / 93$ & 1,0526 & 1,0090 & 1,0432 \\
$1993 / 94$ & 0,9894 & 1,0004 & 0,9891 \\
$1994 / 95$ & 0,9830 & 0,9894 & 0,9936 \\
$1995 / 96$ & 1,0064 & 0,9896 & 1,0170 \\
$1996 / 97$ & 1,0132 & 1,0081 & 1,0051 \\
\hline
\end{tabular}

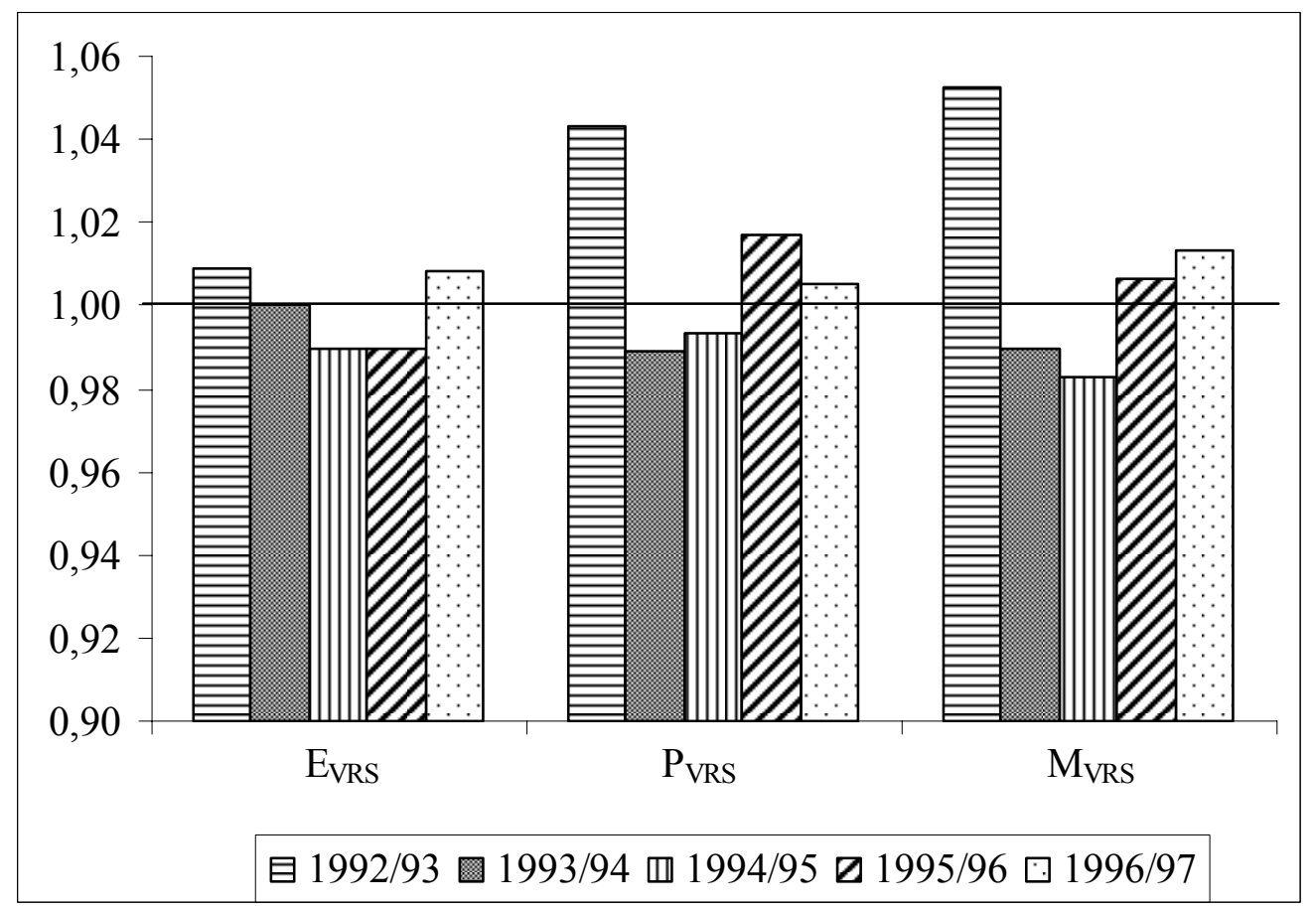

Figure 2. Decomposition of the VRS- Malmquist input based productivity index 
Once again, this table helps to understand what is the key factor explaining the movement in the productivity index. One can see that the changes in efficiency $\left(E^{V R S}\right)$ are relatively small and that the explanation is to be found in the technological change $\left(P^{V R S}\right)$. After a technological regress in 1992/1993, school boards experienced a weak technological progress in 1993/94. And once again, we observe a convergence toward the initial state.

Analyzing the table in Appendix 3, we observe that results for the first period, 1992/93 $1993 / 94$, differ widely from the subsequent periods. This is related to a severe $10 \%$ budget cut decided by the government in order to reach budget equilibria after many years of large deficits. Consequently, the school boards decided to lay off $1 \%$ of their employees, but this was insufficient to maintain their efficiency since the number of students fell by $4 \%$ the same year. As a result the level of efficiency decreased in 1992/93. The Montréal region has not been affected to the same extent because of the immigration which is highly concentrated in this region. This factor prevents the number of students to decrease in Montréal.

At this stage, two questions arise: How can we explain a negative technological change at the beginning of the period followed by an increase immediately after? And how can we explain smaller technological changes for the other periods? The standard decomposition is not sufficient to give an answer. A finer decomposition is required.

As already mentioned the productivity index $M^{V R S}$ can also be decomposed in two terms: a productivity index, $M_{X \bar{K}^{t}}$, with the quasi-fixed inputs stacked at their initial level, and a second productivity index, $M_{\bar{X}^{t+1} K}$, that assesses the impact of quasi-fixed inputs, holding the variable inputs and the outputs at their final level.

As expected, we observe from Table 3 and Figure 3 that the first period does not behave like the others, but we also observe that the other indexes also experience some movements.

In the first period, the movement in the VRS-Malmquist productivity index can be explained essentially by a decrease in the variable-inputs related productivitity index $\left(M_{x \bar{k}^{t}}>1\right)$. This decrease is in large part explained by a technological regress related to the variable inputs $\left(P_{x \bar{k}^{t}}>1\right)$. At this stage, without any research at the school level, it is difficult to explain 
such a regression. Our guess is that this may be related to our choice of including the teachers as a variable input. While this input is clearly variable when the number of students increases, this might not be the case when the number decreases as it was the case. This could be a result of some contractual rigidity.

In the second period, the movement is once again related to the same factor, but here we also see that there is a strong technological progress related to the quasi-fixed factors $\left(P_{\bar{x}^{t+1} k}<1\right)$. Once again, without any field research, one can only express some tentative explanations about this technological progress. A possible explanation is that during this period, new teaching technologies have been introduced, mainly related to new communication technologies. This progress has been totally compensated by a sharp decrease in the management of the quasi-fixed inputs $\left(E_{\bar{x}^{t+1} k}>1\right)$. The result is that the productivity index related to the quasi-fixed inputs $\left(M_{\bar{x}^{t+1} k}\right)$ is roughly equal to 1 . This pattern for $M_{\bar{x}^{t+1} k}$ is reproduced for the remaining years.

$M_{x \bar{k}^{t}}$ is relatively less stable because its components are not stable. A movement in one direction for one component is counterbalanced by an opposite movement for the other component.

Table 3. Second decomposition of the VRS Malmquist productivity index

\begin{tabular}{|c|cc|cc|cc|}
\hline \multirow{2}{*}{ Year } & \multicolumn{2}{|c|}{ Efficiency change } & \multicolumn{2}{|c|}{ Technological change } & \multicolumn{2}{|c|}{ Productivity index } \\
\cline { 2 - 7 } & $E_{x \bar{k}^{t}}$ & $E_{\bar{x}^{t+1} k}$ & $P_{x \bar{k}^{t}}$ & $P_{\bar{x}^{t+1} k}$ & $M_{x \bar{k}^{t}}$ & $M_{\bar{x}^{t+1} k}$ \\
\hline $1992 / 93$ & $1 . .0050$ & 0.9918 & 1.0448 & 1.0108 & 1.0500 & 1.0025 \\
$1993 / 94$ & 0.9997 & 1.0314 & 0.9892 & 0.9701 & 0.9889 & 1.0006 \\
$1994 / 95$ & 0.9861 & 1.0246 & 0.9947 & 0.9781 & 0.9809 & 1.0021 \\
$1995 / 96$ & 0.9890 & 1.0114 & 1.0174 & 0.9888 & 1.0062 & 1.0001 \\
$1996 / 97$ & 0.9985 & 1.0579 & 1.0082 & 0.9514 & 1.0067 & 1.0065 \\
\hline
\end{tabular}




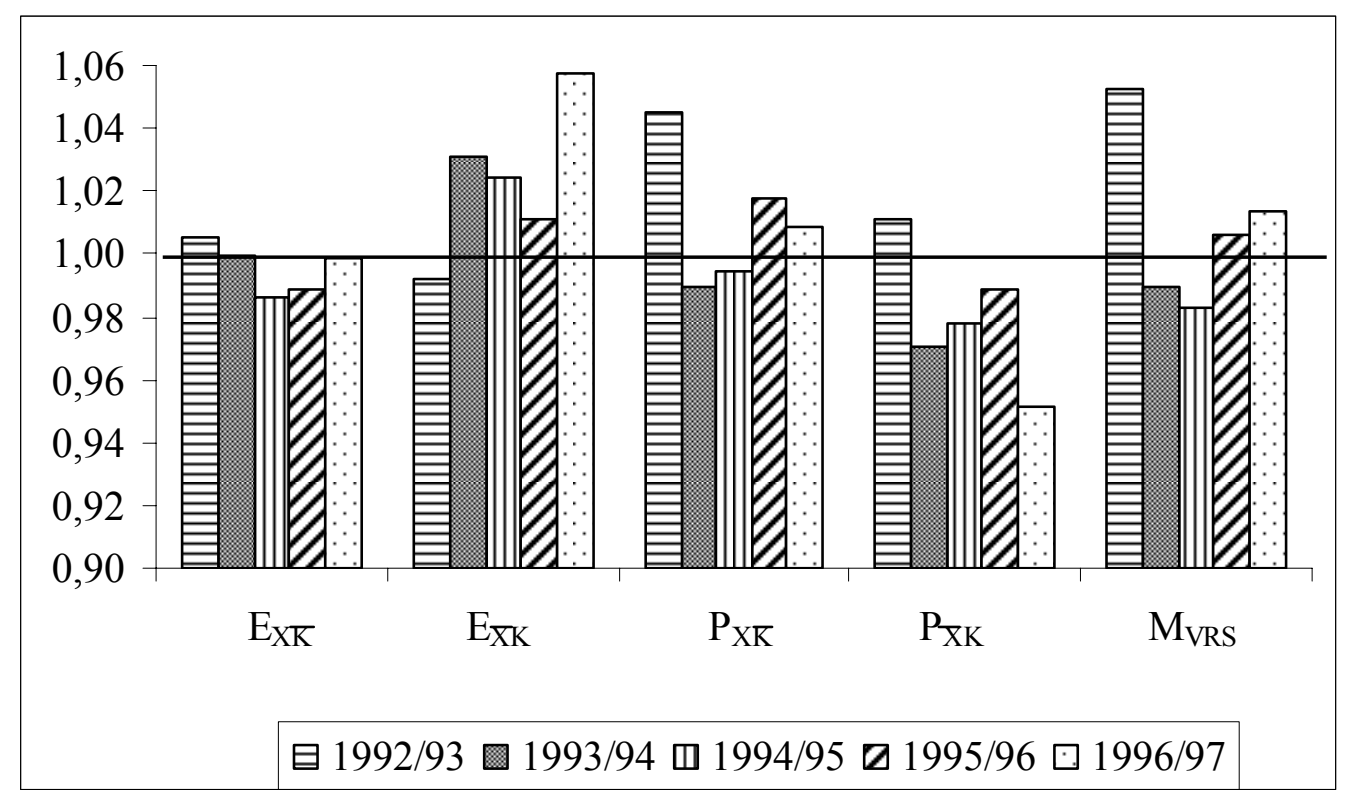

Figure 3. Second decomposition of the VRS-Malmquist input based productivity index

That inverse relationship is interesting. Technological change is a mixture of new technology, mainly associated to new equipment and capital (quasi-fixed inputs), improved management skills and learning-by-doing, mainly associated to variable inputs (labor).

As expected, school districts benefited from technological change associated to quasi-fixed inputs $\left(P_{\bar{x}^{t+1} k}<1\right)$, but the results show that this increase in technological skills had no impact on productivity $\left(M_{\bar{X}^{t+1} K}=P_{\bar{X}^{t+1} K} \times E_{\bar{X}^{t+1} K} \approx 1\right.$ and $\left.M^{V R S} \approx 1\right)$. This suggests that school districts have not been able to transform those technological advances into cost reduction. ${ }^{4}$ Technological change implies a shift of the production frontier, but the status quo in the management implies that the distance between the observed input bundle and the frontier increases. This corresponds to the decrease in efficiency $\left(E_{\bar{X}^{t+1} K}>1\right)$. We could illustrate

\footnotetext{
${ }^{4}$ Note that technological change implies a reduction in input quantities that can be expressed in terms of cost reduction by multiplying the reduction in inputs by their prices.
} 
this in the two inputs case. The technological change is measured by the shift in the isoquant at time $t$ and $t+1$, that is distance $\mathrm{AB}$. The efficiency at time $t$ is measured by the distance between the observation at time $t$, point $\mathrm{C}$, and the frontier, that is distance $\mathrm{BC}$. If the $\mathrm{DMU}$ is unable to adapt to the new technology (point $\mathrm{C}$ represents also the mix of inputs at time $t+1)$, the shift in isoquant merely increase the inefficiency that become CA.

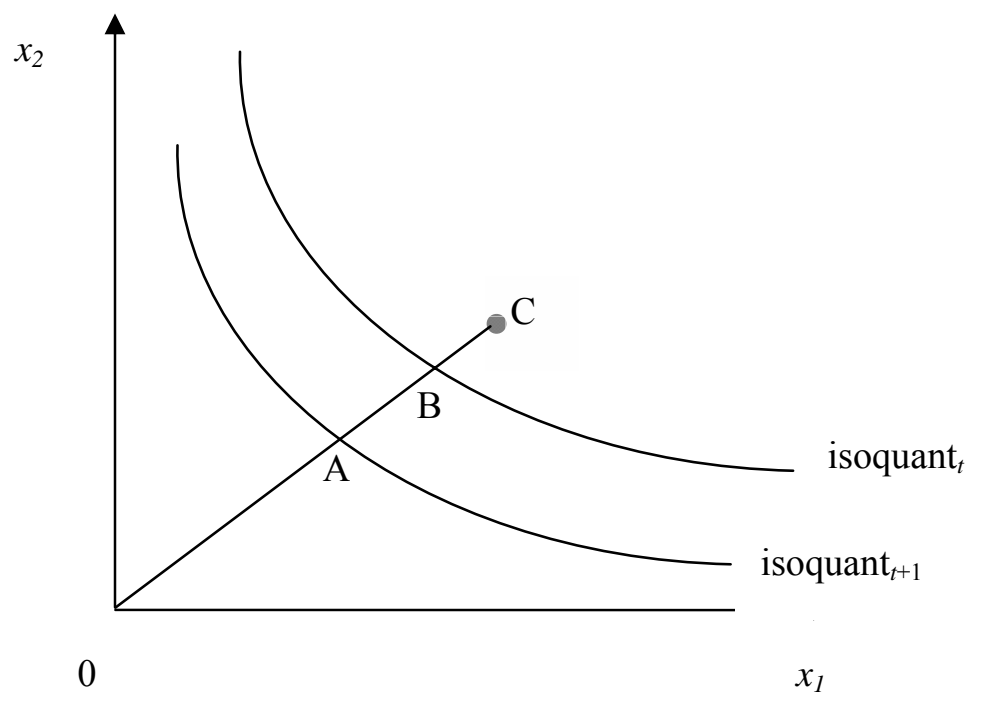

Figure 4. Relation between technological change and inefficiency

This can be easily explained. Québec Department of Education imposes a very stringent regulatory framework to School districts and this is paralleled by a similar framework imposed by school dictricts to every single school under their responsability. Within that framework, school districts have no incentive to introduce new organizational changes. It is much easier to replicate what has been done and accepted by both the school districts and the Départment of Education in the previous years. Once a new technology is introduced ("discovered") in a school district, it takes time before this new technology be incorporated in new organizational settings. So, any new technology would imply additional cost at the beginnings. This phenomenon is well known. In investment theory, this effect is known as one of the source of adjustment cost in investment. 


\section{Conclusion}

The search for efficiency and technological advance is crucial for managers and governments. This task would be easier if it was possible to compare oneself with competitors or with what has been done in the past, but such comparisons require reliable measurement tools. DEA has been proposed as the measurement tool par excellence, but it failed to integrate some constraints. Efficiency and technological change can be measured using methods proposed by Caves et al. (1982), and generalized by Färe et al. (1994). It remains that this method implies that every input is under direct control of the managers and can be freely and immediately adjusted to their optimal level, an assumption too strong in practice.

Our paper is based on a method that takes explicitly into account the fact that some inputs cannot be adjusted instantaneously. We applied that method to the case of school districts in the Province of Québec, Canada. Our results show that quasi-fixed inputs are important in the measurement of efficiency. There is an inverse relation between the change in efficiency and the technological change.

In the most recent years of our sample, school districts have proved succesful in introducing new technologies by means of quasi-fixed inputs, but the converse is true for variable inputs (see Appendix 4). Unfortunately, these gains have been counterbalanced by losses in efficiency.

There remain some open questions. Our results need to be related to some theory about the rapidity to which any technological change is introduced into organizations. There are reasons explaining why the public sectors are so constrained by rules, by-laws and other forms of administrative regulations. Our paper does not say that these rules are bad, but necessarily, it is important to check whether those rules are at the roots of some inefficiencies. If it is the case, then these inefficiencies represent a cost that must be introduced into the evaluation of them.

Finally, an important question is related to the heart of the quasi-fixed model. By definition, non-discretionary inputs cannot be adjusted in the short-run. Some cannot be adjusted at all 
(one can think to the land), but others can be adjusted after some time. Equipment and buildings are such typical inputs. It would be appropriate to incorporate a dynamic model for the choice of capacity, namely, a theory of investment is required. Some papers have been proposed (Nemoto and Goto, 1999 and 2003; Silva and Stefanou, 2003 and 2007; Ouellette and Yan, 2008) in standard DEA models, but it remains to adapt those models in the context of Malmquist indexes. The task is not an easy one. It requires a treatment of expectations that greatly complicates the decomposition between technological change and efficiency change. This is likely to be the next major development in this field of research.

\section{References}

Asmild, M., \& F. Tam (2007). "Estimating Global Frontier Shifts and Global Malmquist Indices.". Journal of Productivity Analysis. Vol 27 n 2, 137-48.

Banker, R. D. and R. C. Morey (1986) "The Use of Categorical Variable in Data Envelopment Analysis.” Management Science, Vol. 32 n. 12, 1613-1627.

Burgess, J. F. Jr, and P. W. Wilson. (1995) "Decomposing Hospital Productivity Changes, 1985-1988: a Nonparametric Malmquist Approach.” Journal of Productivity Analysis, Vol. 6, n.4, 343-363.

Caves, D.W., L.R. Christensen and W.E. Diewert. (1982) "The Economic Theory of Index Numbers and the Measurement of Input, Output and Productivity." Econometrica, Vol. 50 n.6, 1393-1414.

Chakraborty, K., B. Biswas \& W. C. Lewis (2001). "Measurement of Technical Efficiency in Public Education: A Stochastic and Nonstochastic Production Function Approach". Southern Economic Journal. Vol 67 n 4, 889-905.

Coates, D. C., \& D. J. Lamdin (2002). "School Performance Evaluation Using Data Envelopment Analysis". Public Finance and Management. Vol 2 n 4, 566-91.

Färe, R., S. Grosskopf, B. Lindgren and P. Roos. (1994) "Productivity Developments in Swedish Hospitals: A Malmquist Output Index Approach.” in A. Charnes, W. Cooper, A.Y. Lewin and L.M. Seiford (Eds.) Data Envelopment Analysis: Theory, Methodology and Applications. Kluwer Academic Publishers, Boston. 
Farrell, M.J. (1957) "The Measurement of Production Efficiency." Journal of the Royal Statistics Society, Series A, Vol 120, 253-261.

Flegg, A. T. et al. (2004). "Measuring the Efficiency of British Universities: A Multi-period Data Envelopment Analysis". Education Economics. Vol 12 n 3, 231-49.

Gannon, B. (2008). "Total Factor Productivity Growth of Hospitals in Ireland: A Nonparametric Approach". Applied Economics Letters. Vol 15 n 1-3, 131-35.

Grifell-Tatjé, E., and C.A.K. Lovell (1995). "A Note on the Malmquist Productivity Index." Economics Letters, Vol. 47, 169-175.

Grosskopf, S., \& C. Moutray (2001). "Evaluating Performance in Chicago Public Schools in the Wake of Decentralization". Economics of Education Review. Vol 20 n 1, 1-14.

Kirjavainen, T. \& H. A Loikkanen (1998). "Efficiency Differences of Finnish Senior Secondary Schools: An Application of DEA and Tobit Analysis". Economics of Education Review. Vol 17 n 4, 377-94.

Lambert, D.K. (1999). "Scale and the Malmquist Productivity Index." Applied Economics Letters, Vol. 6, 593-596.

Malmquist, S. (1953). "Index Numbers and Indifference Surfaces." Trabajos de estatistica, Vol. 4, 209-242.

Nemoto, J., and M, Goto (1999). "Dynamic Data Envelopment Analysis: Modeling Intertemporal Behavior of a Firm in the Presence of Productive Inefficiencies." Economics Letters, 64, 51-56.

Nemoto, J., and M. Goto (2003). "Measurement of Dynamic Efficiency in Production: An Application of Data Envelopment Analysis to Japanese Electric Utilities." Journal of Productivity Analysis, 19, 191-210.

Ouellette, P. and V. Vierstraete (2004). "Technological Change and Efficiency in the Presence of Quasi-Fixed Inputs: A DEA Application to the Hospital Sector." European Journal of Operational Research, Vol 154. n 3. 755-763.

Ouellette, P. and L. Yan (2008). "Investment and Dynamic DEA". Journal of Productivity Analysis, Vol 29, n 3,. 235- 247.

Puig-Junoy, J. (1998). "Technical Efficiency in the Clinical Management of Critically Ill Patients". Health Economics. Vol 7 n 3, 263-77 
Rassouli-Currier, S. (2007). "Assessing the Efficiency of Oklahoma Public Schools: A Data Envelopment Analysis". Southwestern Economic Review. Vol 34 n 1, 131-44.

Ruggiero, J. (2004). "Performance Evaluation in Education: Modeling Educational Production" in Cooper, W. W.; Seiford, L. M.; Zhu, J., eds. Handbook on data envelopment analysis; 323-48; International Series in Operations Research and Management Science. Boston; Dordrecht and London: Kluwer Academic

Silva, E., and S. Stefanou (2003). "Nonparametric Dynamic Production Analysis and the Theory of Cost." Journal of Productivity Analysis, 19, 5-32.

Silva, E., and S. Stefanou (2007). "Dynamic Efficiency Measurement: Theory and Application.” American Journal of Agricultural Economics, 89, 398-419.

Solow, R.M. (1957). “Technical Change and the Aggregate Production Function." Review of Economics and Statistics, Vol. 39, 312-320.

Steinmann, L., G. Dittrich, A. Karmann and P. Zweifel (2004). "Measuring and Comparing the (In)Efficiency of German and Swiss Hospitals". The European Journal of Health Economics, Vol. 5, n 3, 216-226

Worthington, A. C. \& B. L. Lee (2008). "Efficiency, Technology and Productivity Change in Australian Universities, 1998-2003". Economics of Education Review. Vol 27 n 3, 28598.

Zofio, J. (2007). "Malmquist Productivity Index Decompositions: A Unifying Framework." Applied Economics. Vol:39 n 18, 2371-2387. 
Appendix 1: Descriptive statistics (852 obs.)

\begin{tabular}{|c|c|c|c|c|c|c|}
\hline Type & Variable & Unit & Mean & Minimum & Maximum & Median \\
\hline \multirow{5}{*}{$\begin{array}{l}\text { Variables } \\
\text { inputs }\end{array}$} & Teachers & $\begin{array}{l}\text { Full time } \\
\text { equivalent }\end{array}$ & 484.18 & 22.50 & $7,030.0$ & 337.25 \\
\hline & $\begin{array}{c}\text { Non } \\
\text { teaching } \\
\text { employees }\end{array}$ & $\begin{array}{l}\text { Full time } \\
\text { equivalent }\end{array}$ & 242.10 & 8.30 & $4,255.80$ & 159.25 \\
\hline & Material & $\begin{array}{l}\text { Quantity } \\
\text { Index }\end{array}$ & 25,664 & 511 & 546,193 & 17,024 \\
\hline & Energy & $\begin{array}{l}\text { Quantity } \\
\text { Index }\end{array}$ & 7,075 & 972 & 34,642 & 6,493 \\
\hline & Other & $\begin{array}{l}\text { Quantity } \\
\text { Index }\end{array}$ & 74,167 & 957 & 766,229 & 53,634 \\
\hline $\begin{array}{l}\text { Quasi- } \\
\text { fixed } \\
\text { input }\end{array}$ & Buildings & $\begin{array}{l}\text { Square } \\
\text { meters }\end{array}$ & 110,255 & 3,437 & $1,829,562$ & 81,740 \\
\hline \multirow{2}{*}{ Outputs } & $\begin{array}{c}\text { Primary } \\
\text { school } \\
\text { students }\end{array}$ & $\begin{array}{l}\text { Full time } \\
\text { equivalent }\end{array}$ & $4,048.27$ & 141.5 & $54,592.0$ & $2,829.25$ \\
\hline & $\begin{array}{l}\text { Secondary } \\
\text { school } \\
\text { students }\end{array}$ & $\begin{array}{l}\text { Full time } \\
\text { equivalent }\end{array}$ & $3,520.56$ & 134.0 & $54,490.53$ & $2,553.65$ \\
\hline
\end{tabular}


Appendix 2. Decomposition of the CRS-productivity index

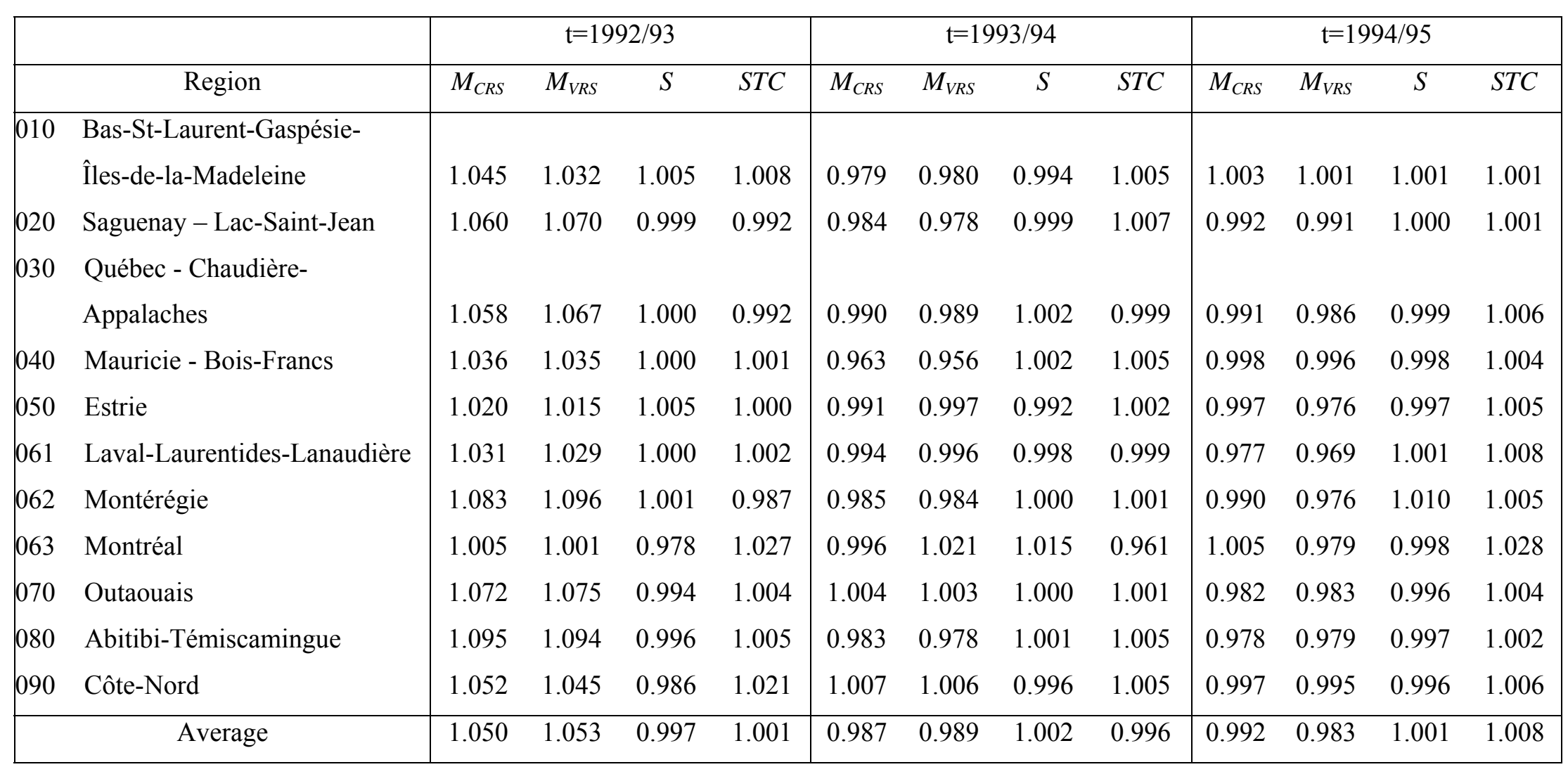




\begin{tabular}{|c|c|c|c|c|c|c|c|c|c|}
\hline \multirow{2}{*}{\multicolumn{2}{|c|}{ Region }} & \multicolumn{4}{|c|}{$\mathrm{t}=1995 / 96$} & \multicolumn{4}{|c|}{$t=1996 / 97$} \\
\hline & & $M_{C R S}$ & $M_{V R S}$ & $S$ & STC & $M_{C R S}$ & $M_{V R S}$ & $S$ & STC \\
\hline \multirow[t]{2}{*}{010} & Bas-St-Laurent-Gaspésie- & & & & & & & & \\
\hline & Îles-de-la-Madeleine & 0.985 & 0.986 & 0.996 & 1.003 & 1.009 & 1.009 & 1.008 & 0.992 \\
\hline 020 & Saguenay - Lac-Saint-Jean & 1.022 & 1.033 & 1.002 & 0.987 & 1.020 & 1.021 & 0.999 & 1.000 \\
\hline \multirow[t]{2}{*}{030} & Québec - Chaudière- & & & & & & & & \\
\hline & Appalaches & 1.003 & 1.008 & 1.004 & 0.991 & 1.015 & 1.021 & 0.995 & 0.999 \\
\hline 040 & Mauricie - Bois-Francs & 0.992 & 0.994 & 0.999 & 0.999 & 1.007 & 1.007 & 1.001 & 0.999 \\
\hline 050 & Estrie & 1.002 & 1.006 & 0.999 & 0.998 & 0.992 & 0.993 & 1.009 & 0.991 \\
\hline \multirow[t]{2}{*}{061} & Laval-Laurentides- & & & & & & & & \\
\hline & Lanaudière & 0.993 & 0.991 & 0.999 & 1.003 & 0.967 & 0.974 & 1.001 & 0.992 \\
\hline 062 & Montérégie & 1.002 & 1.012 & 0.995 & 0.995 & 0.991 & 0.999 & 1.007 & 0.986 \\
\hline 063 & Montréal & 0.993 & 1.022 & 0.996 & 0.975 & 0.997 & 1.074 & 1.003 & 0.926 \\
\hline 070 & Outaouais & 1.001 & 1.001 & 1.002 & 0.998 & 0.996 & 0.997 & 0.998 & 1.001 \\
\hline 080 & Abitibi-Témiscamingue & 1.005 & 1.000 & 1.001 & 1.004 & 1.003 & 1.008 & 1.006 & 0.989 \\
\hline \multirow[t]{2}{*}{090} & Côte-Nord & 0.996 & 0.994 & 0.998 & 1.004 & 1.012 & 0.993 & 1.015 & 1.004 \\
\hline & Average & 0.999 & 1.006 & 0.999 & 0.994 & 0.999 & 1.013 & 1.002 & 0.984 \\
\hline
\end{tabular}


Appendix 3: First decomposition of the VRS-productivity index

\begin{tabular}{|c|c|c|c|c|c|c|c|c|c|c|c|c|c|c|c|c|}
\hline \multirow{2}{*}{\multicolumn{2}{|c|}{ Region }} & \multicolumn{3}{|c|}{$\begin{array}{c}t=1992 / 93 \\
t+1=1993 / 94\end{array}$} & \multicolumn{3}{|c|}{$\begin{array}{c}t=1993 / 94 \\
t+1=1994 / 95\end{array}$} & \multicolumn{3}{|c|}{$\begin{array}{c}t=1994 / 95 \\
t+1=1995 / 96\end{array}$} & \multicolumn{3}{|c|}{$\begin{array}{c}t=1995 / 96 \\
t+1=1996 / 97\end{array}$} & \multicolumn{3}{|c|}{$\begin{array}{c}t=1996 / 97 \\
t+1=1997 / 98\end{array}$} \\
\hline & & $M^{V R S}$ & $E^{V R S}$ & $P^{V R S}$ & $M^{V R S}$ & $E^{V R S}$ & $P^{V R S}$ & $M^{V R S}$ & $E^{V R S}$ & $P^{V R S}$ & $M^{V R S}$ & $E^{V R S}$ & $P^{V R S}$ & $M^{V R S}$ & $E^{V R S}$ & $P^{V R S}$ \\
\hline 010 & Bas-St-Laur.-G.-Îles-Mad. & 1.032 & 0.988 & 1.044 & 0.980 & 0.994 & 0.986 & 1.001 & 1.008 & 0.993 & 0.986 & 0.976 & 1.010 & 1.009 & 0.998 & 1.012 \\
\hline 020 & Saguenay - Lac-St-Jean & 1.070 & 1.004 & 1.066 & 0.978 & 0.992 & 0.986 & 0.991 & 0.987 & 1.004 & 1.033 & 0.998 & 1.035 & 1.021 & 0.998 & 1.023 \\
\hline 030 & Qc - Chaudière-App. & 1.067 & 1.009 & 1.057 & 0.989 & 1.001 & 0.988 & 0.986 & 0.994 & 0.992 & 1.008 & 0.981 & 1.028 & 1.021 & 1.012 & 1.009 \\
\hline 040 & Mauricie - Bois-Francs & 1.035 & 1.014 & 1.021 & 0.956 & 0.983 & 0.973 & 0.996 & 0.985 & 1.011 & 0.994 & 0.996 & 0.998 & 1.007 & 1.005 & 1.001 \\
\hline 050 & Estrie & 1.015 & 1.022 & 0.993 & 0.997 & 0.995 & 1.002 & 0.976 & 0.987 & 0.989 & 1.006 & 1.002 & 1.003 & 0.993 & 1.035 & 0.959 \\
\hline 061 & Laval-Laur.-Lanaud. & 1.029 & 1.012 & 1.016 & 0.996 & 1.002 & 0.994 & 0.969 & 0.979 & 0.990 & 0.991 & 0.991 & 1.000 & 0.974 & 1.005 & 0.969 \\
\hline 062 & Montérégie & 1.096 & 1.012 & 1.079 & 0.984 & 1.000 & 0.983 & 0.976 & 0.990 & 0.986 & 1.012 & 0.993 & 1.019 & 0.999 & 1.012 & 0.988 \\
\hline 063 & Montréal & 1.001 & 1.016 & 1.016 & 1.021 & 1.017 & 1.004 & 0.979 & 0.990 & 0.989 & 1.022 & 0.996 & 1.026 & 1.074 & 1.010 & 1.064 \\
\hline 070 & Outaouais & 1.075 & 0.985 & 1.044 & 1.003 & 1.011 & 0.992 & 0.983 & 0.984 & 0.998 & 1.001 & 0.985 & 1.016 & 0.997 & 1.014 & 0.983 \\
\hline 080 & Abitibi-Témiscamingue & 1.094 & 1.056 & 1.036 & 0.978 & 0.991 & 0.987 & 0.979 & 0.976 & 1.003 & 1.000 & 0.987 & 1.013 & 1.008 & 0.990 & 1.017 \\
\hline 090 & Côte-Nord & 1.045 & 1.008 & 1.036 & 1.006 & 1.013 & 0.993 & 0.995 & 0.997 & 0.997 & 0.994 & 0.982 & 1.013 & 0.993 & 1.009 & 0.983 \\
\hline & Average & 1.053 & 1.009 & 1.043 & 0.989 & 1.000 & 0.989 & 0.983 & 0.989 & 0.994 & 1.006 & 0.990 & 1.017 & 1.013 & 1.008 & 1.005 \\
\hline
\end{tabular}


Appendix 4: Second decomposition of the VRS-productivity index

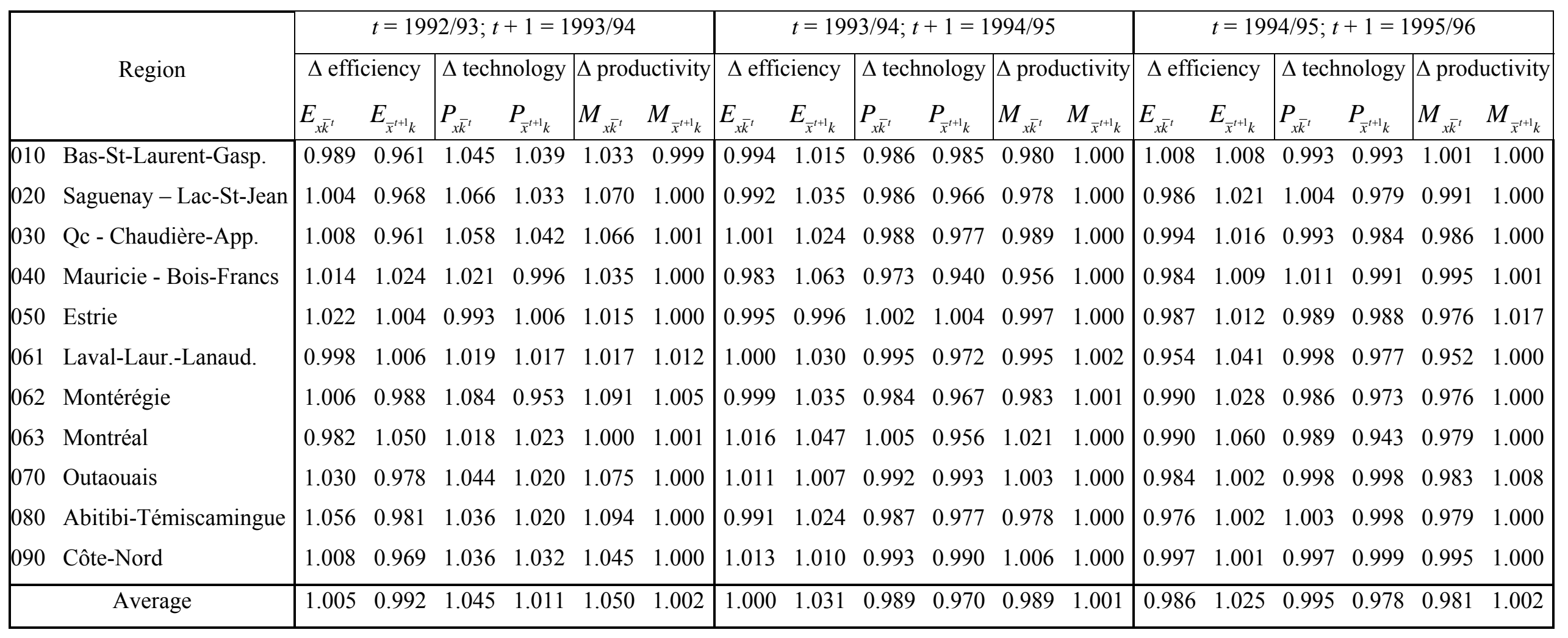




\begin{tabular}{|c|c|c|c|c|c|c|c|c|c|c|c|c|c|}
\hline & \multirow{3}{*}{ Region } & \multicolumn{6}{|c|}{$t=1995 / 96 ; t+1=1996 / 97$} & \multicolumn{6}{|c|}{$t=1996 / 97 ; t+1=1997 / 98$} \\
\hline & & \multicolumn{2}{|c|}{$\Delta$ efficiency } & \multicolumn{2}{|c|}{$\Delta$ technology } & \multicolumn{2}{|c|}{$\Delta$ productivity } & \multicolumn{2}{|c|}{$\Delta$ efficiency } & \multicolumn{2}{|c|}{$\Delta$ technology } & \multicolumn{2}{|c|}{$\Delta$ productivity } \\
\hline & & $E_{x \bar{k}^{t}}$ & $E_{\bar{x}^{t+1} k}$ & $P_{x \bar{k}^{t}}$ & $P_{\bar{x}^{t+1} k}$ & $M_{\chi \bar{k}^{t}}$ & $M_{\bar{x}^{t+1} k}$ & $E_{x \bar{k}^{t}}$ & $E_{\bar{x}^{t+1} k}$ & $P_{x \bar{k}^{t}}$ & $P_{\bar{x}^{t+1} k}$ & $M_{\chi \bar{k}^{t}}$ & $M_{\bar{X}^{t+1} k}$ \\
\hline \multirow[t]{2}{*}{010} & Bas-St-Laurent-Gaspésie- & & & & & & & & & & & & \\
\hline & Îles-de-la-Madeleine & 0.976 & 0.990 & 1.010 & 1.010 & 0.986 & 1.000 & 0.998 & 0.995 & 1.012 & 1.004 & 1.010 & 1.000 \\
\hline \multirow{3}{*}{$\begin{array}{l}020 \\
030\end{array}$} & Saguenay - Lac-Saint-Jean & 0.998 & 1.015 & 1.035 & 0.985 & 1.033 & 1.000 & 0.982 & 1.073 & 1.030 & 0.940 & 1.012 & 1.009 \\
\hline & Québec - Chaudière- & & & & & & & & & & & & \\
\hline & Appalaches & 0.979 & 0.994 & 1.029 & 1.007 & 1.007 & 1.001 & 1.009 & 1.022 & 1.010 & 0.980 & 1.020 & 1.002 \\
\hline 040 & Mauricie - Bois-Francs & 0.996 & 1.041 & 0.999 & 0.960 & 0.995 & 0.999 & 0.989 & 1.076 & 1.007 & 0.939 & 0.996 & 1.011 \\
\hline 050 & Estrie & 1.002 & 0.995 & 1.003 & 1.005 & 1.006 & 1.000 & 1.035 & 1.055 & 0.959 & 0.948 & 0.993 & 1.000 \\
\hline \multirow[t]{2}{*}{061} & Laval-Laurentides- & & & & & & & & & & & & \\
\hline & Lanaudière & 0.991 & 1.020 & 1.001 & 0.980 & 0.992 & 0.999 & 0.968 & 1.130 & 0.975 & 0.914 & 0.943 & 1.033 \\
\hline 062 & Montérégie & 0.993 & 1.003 & 1.020 & 0.997 & 1.013 & 1.000 & 1.012 & 1.070 & 0.985 & 0.936 & 0.997 & 1.002 \\
\hline 063 & Montréal & 0.996 & 1.051 & 1.026 & 0.952 & 1.022 & 1.000 & 0.996 & 1.074 & 1.076 & 0.934 & 1.071 & 1.003 \\
\hline 070 & Outaouais & 0.985 & 0.993 & 1.016 & 1.007 & 1.001 & 1.000 & 1.012 & 1.046 & 0.982 & 0.959 & 0.994 & 1.003 \\
\hline 080 & Abitibi-Témiscamingue & 0.987 & 0.991 & 1.013 & 1.010 & 1.000 & 1.000 & 0.990 & 0.993 & 1.018 & 1.008 & 1.007 & 1.000 \\
\hline \multirow[t]{2}{*}{090} & Côte-Nord & 0.982 & 0.986 & 1.013 & 1.014 & 0.994 & 1.000 & 1.009 & 1.045 & 0.983 & 0.957 & 0.993 & 1.000 \\
\hline & Average & 0.989 & 1.011 & 1.017 & 0.989 & 1.006 & 1.000 & 0.998 & 1.058 & 1.008 & 0.951 & 1.007 & 1.006 \\
\hline
\end{tabular}

